\title{
Muscle Pain, Fear-Avoidance Model
}

\section{Goubert, L., Crombez, G., \& Vlaeyen, J.W.S.}

\section{Synonyms}

Kinesiophobia; pain-related fear; fear of pain; fear-avoidance model

\section{Definition}

Fear-avoidance models explain how and why patients experiencing acute pain may become chronic sufferers and become trapped into a vicious circle of more pain and disability. Common in these models is their focus upon the role of pain-related fear (fear of pain, fear of movement / (re)injury) and dynamic learning processes (avoidance learning).

\section{Characteristics}

Pain is more than an unpleasant perceptual and emotional experience. It elicits innate responses and action tendencies that prepare and facilitate escape from pain (Eccleston and Crombez 1999). Pain is an experience that drives learning. The relevance of learning in chronic pain has been recognised early on in the field of pain (Fordyce 1976) and continues to play a role in more recent biopsychosocial accounts of chronic pain (Asmundson et al. 2004; Gatchel et al., 2007; Vlaeyen and Linton, 2000).

Fordyce (1976) was the first to apply the principles of operant conditioning to the problems of chronic pain patients. The central idea was that "pain behaviour" (e.g. verbal complaints, medication use, bed rest, avoidance of home and work responsibilities) should be conceived of as behaviours that are learned and maintained by their positive consequences (empathy from solicitous spouses, access to pain medications, financial compensation, avoidance of pain-worsening activities or escape from distressing events). In the context of fear-avoidance models, the principles of classical conditioning and operant conditioning are of paramount importance. Much behaviour is learned because it permits the person to avoid or postpone an aversive experience. What exactly is avoided may vary considerably between persons. An obvious example of avoidance behaviour is that patients learn to avoid pain. Some patients do not avoid activities because of anticipated pain, but because they fear that these activities may lead to (re)injury (Kori et al. 1990). It may also be true that pain behaviours are maintained by the avoidance of aversive experiences that are not at all related to pain. A popular example is that pain behaviour and, in particular sick leave, may be reinforced and maintained by the avoidance of aversive and unsatisfying work conditions. Whenever these extra benefits outweigh the costs of pain behaviour, one talks about secondary gain. Although clinical practice suggests that secondary gain does occur, its incidence is probably overestimated. It is often overlooked that the presence of pain also creates distress and frustration at work. Patients, whose pain interferes with their valued professional activities, may not resume work because they avoid these distressing and frustrating experiences.

Building upon the model of Lethem et al. (1983), the cognitive-behavioural model of fear of movement / (re)injury was developed to explain the development of chronic suffering in non-specific low back pain. Vlaeyen and Linton (2000) postulated two extreme responses to pain, namely confrontation and avoidance. As depicted in Figure 1, a gradual confrontation and resumption of daily activities despite pain is considered as an adaptive response that eventually leads to the reduction of fear, the encouragement of physical recovery and functional rehabilitation. In contrast, a catastrophic interpretation of pain is considered as a maladaptive response that initiates a vicious circle in which fear of movement / (re)injury and the subsequent avoidance of activities augment functional disability and the pain experience by means of hypervigilance, depression, and disuse (Vlaeyen and Linton 2000; Leeuw et al., 2007). The latter response is also known as kinesiophobia.

Several empirical studies have provided support for these central ideas. First, pain catastrophizing, an exaggerated negative orientation towards actual or anticipated pain experiences, has been found to be strongly related to pain-related fear (e.g. Goubert et al. 2006b; Vlaeyen and Linton 2000). Second, fear of movement / (re)injury has been found to be characterized by escape and avoidance behaviours and to lower the ability to accomplish daily living tasks. Patients who are afraid of pain or of (re)injuring 
themselves during physical activities tend to avoid physical activities or are reluctant to perform vigorously during standard physical tests (Crombez et al. 1999, see video extract). Because avoidance behaviours occur in anticipation of pain rather than as a response to pain, opportunities are limited to correct (erroneous) beliefs about their pain. As a consequence, pain-related fear and avoidance may become resistant and persistent (e.g. Crombez et al. 1999; Vlaeyen and Crombez 1999). Prospective studies have further substantiated the important and unique role of pain-related fear and avoidance as predictors of chronic pain problems (Jensen et al., 2009; Klenerman et al. 1995; Linton et al. 2000). Third, excessive avoidance of physical activities may have detrimental physical and psychological consequences. A decrease in mobility, decreased muscle strength, and loss of fitness can occur, possibly resulting in a 'disuse syndrome' (Verbunt et al. 2003). Avoidance can also result in loss of self-esteem, deprivation of reinforcers, depression and worrying. Fourth, pain-related fear has been found to be related to a hypervigilance for pain (Goubert et al. 2004b) and a difficulty in switching attention away from pain (Eccleston and Crombez 1999). This pattern of hypervigilance in fearful chronic pain patients may further diminish the ability to perform everyday activities and hamper the recruitment of pain coping strategies (Eccleston and Crombez 1999; McCracken and Gross 1993). Recently, the fearavoidance model has been applied to other populations, e.g., elderly individuals (Kempen et al., 2009). Also, the model has been argued to be valid to explain the development of persistent complaints after an acute whiplash injury (Vangronsveld et al., 2007).

Fear-avoidance models are dynamic in that both pain-related fear and avoidance are not static or stable characteristics of the individual (Goubert et al. 2006b), but are the result of complex interactions that are typical for a biopsychosocial perspective. Catastrophic thinking about pain and pain-related fear do not emerge within a social and cultural vacuum. In Western cultures many - even pain-free - persons hold a biomedical view of back pain. As a consequence, many believe that back pain is caused by an injury, that a wrong movement can lead to serious problems if one has back pain, that X-ray and imaging tests can always identify the cause of back pain and that bed rest is an important part of treatment (Goubert et al. 2004a). Health-care providers may further reinforce these beliefs, inadvertently, fuelling pain-related fear and avoidance. Indeed, studies have demonstrated that many health care providers still advise patients to avoid painful movements and believe that pain-reduction is a necessary requirement for return to work or that sick-leave is an adequate treatment for back pain (Linton et al., 2002; Coudeyre et al., 2006).

One of the clinical implications of the fear-avoidance models is that treatment should directly target painrelated fear and avoidance. Therefore, in analogy with phobia and anxiety disorders, exposure in vivo has been proposed as a potentially effective treatment of pain-related fear (Vlaeyen et al. 2002). During exposure, patients are gradually exposed to physical activities that are feared or believed to be harmful, in order to correct erroneous cognitions and to extinguish fear and avoidance. At present, several studies have demonstrated the effectiveness of exposure in vivo for reducing pain-related fear, pain catastrophizing and disability (Leeuw et al., 2008; Vlaeyen et al. 2002).

\section{References}

1. Asmundson GJG, Vlaeyen JWS, Crombez G (2004) Understanding and treating fear of pain. Oxford University Press, Oxford, p 367

2. Coudeyre E, Rannou F, Tubach F, Baron G, Coriat F, Brin S, Revel M, Poiraudeau S (2006) General practitioners' fear-avoidance beliefs influence their management of patients with low back pain. Pain 124:330-337

3. Crombez G, Vlaeyen JWS, Heuts PHTG et al. (1999) Pain-related fear is more disabling than pain itself: evidence on the role of pain-related fear in chronic back pain disability. Pain 80:329-339

4. Eccleston C, Crombez G (1999) Pain demands attention: a cognitive-affective model of interruptive function of pain. Psychol Bull 3:356-366

5. Fordyce W E (1976). Behavioral methods for chronic pain and illness. The C.V. Mosby Company, Saint Louis

6. Gatchel RE, Peng YB, Peters ML, Fuchs PN, Turk DC (2007) The biopsychosocial approach to chronic pain: Scientific advances and future directions. Psychol Bull 133:581-624

7. Goubert L, Crombez G, De Bourdeaudhuij I (2004a) Low back pain, disability and back pain myths in a community sample: prevalence and interrelationships. European J Pain 8:385-394

8. Goubert L, Crombez G, Van Damme S (2004b) The role of neuroticism, pain catastrophizing and pain-related fear in vigilance to pain: a structural equations approach. Pain 107:234-241

9. Jensen JN, Albertsen K, Borg V, Nabe-Nielsen K (2009) The predictive effect of fear-avoidance beliefs on low back pain among newly qualified health care workers with and without previous low back pain: a prospective cohort study. BMC Musculoskeletal Disorders 10:117

10. Kempen GIJM, van Haastregt JCM, Mckee KJ, Delbaere K, Zijlstra GAR (2009) Socio-demographic health-related and psychosocial correlates of fear of falling and avoidance of activity in community-living older persons who avoid activity due to fear of falling. BMC Public Health 9:170

11. Klenerman L, Slade PD, Stanley M et al. (1995) The prediction of chronicity in patients with an acute attack of low back pain in a general practice setting. Spine 20:478-484

12. Kori SH, Miller RP, Todd DD (1990) Kinesiophobia: a new view of chronic pain behavior. Pain Manage Jan / Feb:35- 
13. Leeuw M, Goossens MEJB, Linton SJ, Crombez G, Boersma K, Vlaeyen JWS (2007) The fear-avoidance model of musculoskeletal pain: Current state of scientific evidence. J Behav Med 30:77-94

14. Leeuw M, Goossens MEJB, van Breukelen GJP, de Jong JR, Heuts PHTG, Smeets RJEM, Koke AJA, Vlaeyen JWS (2008) Exposure in vivo versus operant graded activity in chronic low back pain patients: Results of a randomized controlled trial. Pain 138:192-207

15. Lethem J, Slade PD, Troup JD et al. (1983) Outline of a fear-avoidance model of exaggerated pain perception: I. Behav Res Ther 21:401-408

16. Linton SJ, Buer N, Vlaeyen JWS et al. (2000). Are fear-avoidance beliefs related to the inception of an episode of back pain? A prospective study. Psychol Health 14:1051-1059

17. Linton SJ, Vlaeyen JWS, Ostelo RW (2002). The back pain beliefs of health care providers: are we fear-avoidant? J Occup Rehabil 12:223-232

18. McCracken LM, Gross RT (1993) Does anxiety affect coping with chronic pain? Clin J Pain 9:253-259

19. Vangronsveld K, Peters M, Goossens M, et al (2007) Applying the fear-avoidance model to the chronic whiplash syndrome. Pain 131:258-261.

20. Vlaeyen JWS, Crombez G (1999) Fear of movement / (re)injury, avoidance and pain disability in chronic low back pain patients. Man Ther 4:187-195

21. Vlaeyen JWS, Linton SJ (2000) Fear-avoidance and its consequences in chronic musculoskeletal pain: a state of the art. Pain 85:317-332

22. Vlaeyen JWS, de Jong JR, Sieben JM et al. (2002) Graded exposure in vivo for pain-related fear. In: Turk DC, Gatchel RJ (eds) Psychological approaches to pain management: a practitioner's handbook. The Guilford Press, New York, pp 210-233

23. Verbunt JA, Seelen HA, Vlaeyen JWS et al. (2003) Disuse and deconditioning in chronic low back pain: concepts and hypotheses on contributing mechanisms. Eur J Pain 7:9-21

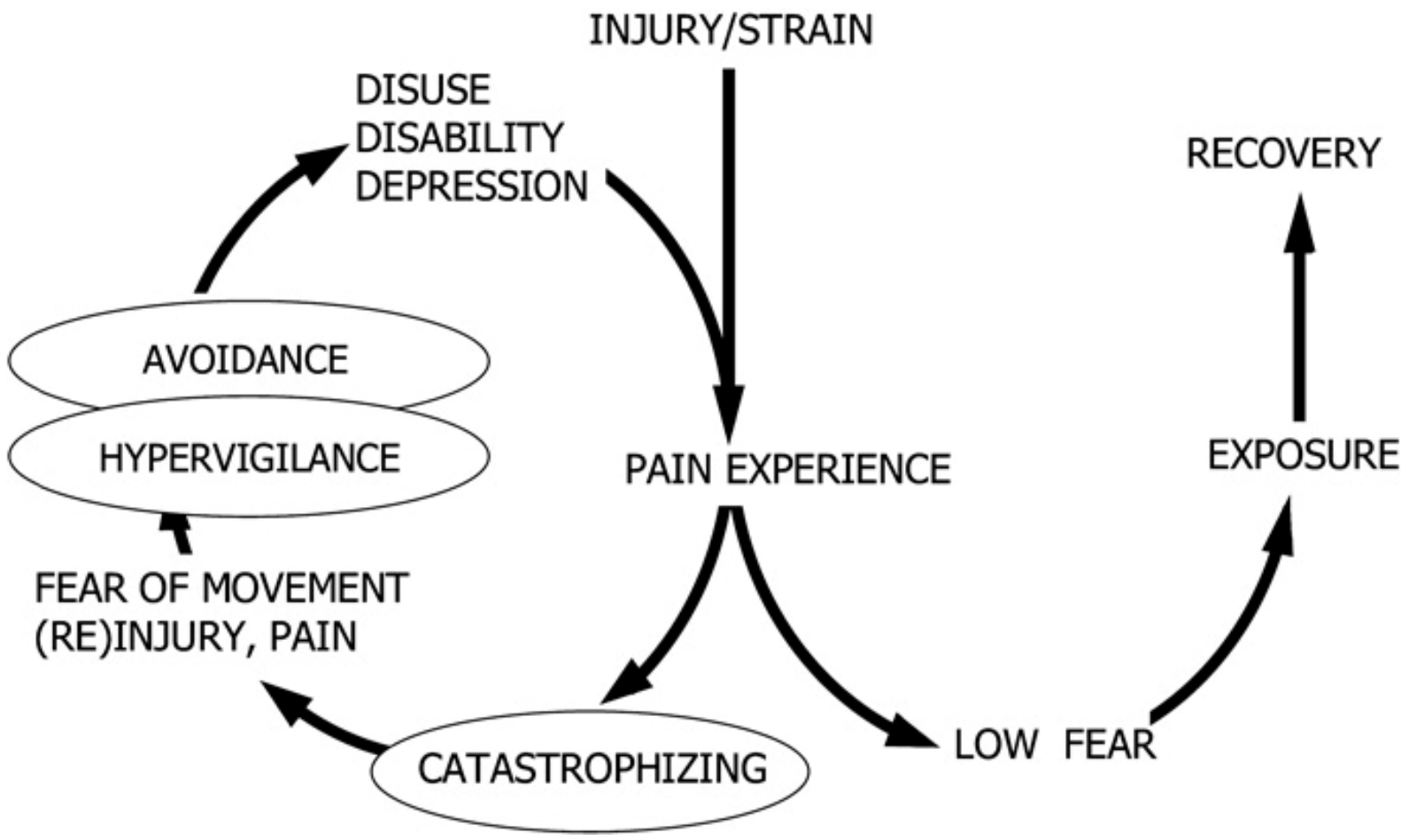

Figure 1 Confrontation to pain. 